\title{
Aplicaciones del Propóleo en Ciencias de la salud.
}

Applications of the Propóleo in

Sciences of the health.

Fecha de Recepción

5 de abril de $201 \mathrm{I}$
Aplicações do Propóleo em

Ciências da Saúde.
Patricia Alejandra Vaculik

Odontóloga. Auxiliar de Primera Categoría Interina. Cátedra Práctica Clínica Preventiva II.

E-mail:patriciavaculik@hotmail.com

\section{Beatriz Cardozo}

Odontóloga. Profesora Titular.

Cátedra Práctica Clínica Preventiva II.

E-mail:malusacardozo2@hotmail.com

Silvia Rita Pérez

Odontóloga. Profesora Adjunta.

Cátedra Práctica Clínica Preventiva II.

E-mail: til_27@hotmail.com

Roque Oscar Rosende Odontólogo. Profesor Titular. CátedraTécnicas

Quirúrgicas y Anestésicas.

E-mail: oscarrosende@hotmail.com

Rolando Pablo Juárez Odontólogo. Profesor Titular.

Cátedra Fisiología Humana.

E-mail: ropablojuarez@gmail.com

\section{Resumen}

El propóleo es un producto natural con propiedades benéficas para la salud humana, tales como: antiinflamatorio, antitumoral, antioxidante y antimicrobiano.

Es necesario conocer el potencial terapéutico del propóleo, para su correcta aplicación clínica, desarrollar productos farmacológicos que ofrezcan seguridad y confianza a nuestros pacientes; estableciéndose estándares de control de calidad adecuados.

El objetivo de esta revisión bibliográfica es presentar y discutir evidencia científicamente contrastada sobre las posibilidades de la utilización del propóleo en las Ciencias de la Salud.

\section{Palabras Claves}

Propóleo. Apis mellifera. Aplicación Clínica.

\section{Abstract}

The propóleo is a natural product with charitable properties for the human health, such as: antiinflammatory, antitumoral, antirust and antimicrobial.

It is necessary to know the therapeutic potential of the propóleo, for his correct clinical application, to develop pharmacological products that offer safety and confidence to our patients; suitable standards of quality control being established. The aim of this bibliographical review is to present and to discuss evidence scientific confirmed on the possibilities of the utilization of the propóleo in the Sciences of the Health. 
Keywords

Apis mellifera- propolis- Clinical application.

\section{Resumo}

A própolis é um produto natural com propriedades benéficas para a saúde humana, tais como anti-inflamatória, antitumoral, antioxidante e antimicrobiana. É necessário conhecer o potencial terapêutico do propóleo, para sua correcta aplicação clínica, desenvolver produtos farmacológicos que ofereçam segurança e confiança a nossos pacientes; estabelecendo-se estándares de controle de qualidade adequados.

O objectivo desta revisão bibliográfica é apresentar e discutir evidência cientificamente contrastada sobre as possibilidades da utilização do propóleo nas Ciências da Saúde.

\section{Palavras chave}

própolis. Apis mellifera. Aplicación Clínica.

\section{Introducción}

El término "propóleo" proviene del griego pro, para o en la defensa, y polis, la ciudad; dando como resultado la palabra "propolis" que significa para la defensa de la colmena (la ciudad de las abejas)'.

Las abejas melíferas (Apis mellifera) elaboran propóleo a partir de cera que ellas producen y con la cual mezclan tierra, polen y resinas de árboles que recolectan en los brotes, cortezas y botones florales; también agregan sus propias enzimas salivares. El propóleo actua como defensa frente al ataque de virus y bacterias así como de hongos y protozoarios, también para regula la humedad y temperatura de la colmena, la protege de los ruidos fuertes, le da estructura y firmeza, evitando las vibraciones producidas por los vientos ${ }^{2,3}$.

El propóleo contiene una amplia variedad de compuestos químicos; se han identificado más de 300 , tales como polifenoles (flavonoides, ácidos fenólicos y sus ésteres, aldehídos, alcoholes y cetonas fenólicas), terpenoides, esteroides, aminoácidos, y compuestos inorgánicos. Sin embargo, la composición de este producto de la colmena es altamente variable y dependiente de la flora local en el sitio de recolección ${ }^{4}$.

Así, en los propóleos argentinos, se han identificado más de 160 compuestos, de los cuales un
$50 \%$ son compuestos fenólicos, a los cuales se les atribuye acción farmacológica. Los principales fenoles identificados son: flavonoides, ácidos aromáticos y sus ésteres, aldehídos aromáticos, cumarinas, triglicéridos fenólicos ${ }^{5}$.

El objetivo de esta revisión de la literatura internacional es suministrar información actualizada del uso del propóleo en las diferentes disciplinas científicas que integran las Ciencias de la Salud.

\section{Apiterapia}

Desde 1978 la OMS ha estado promoviendo y desarrollando las medicinas alternativas $y$ terapias naturales con eficiencia científicamente demostrada en los servicios nacionales de salud en cada país. (OMS, OPS. Estrategia de la Organización Mundial de la Salud sobre Medicina Natural y Tradicional, 2002-2005) ${ }^{6}$.

La apiterapia es un tratamiento terapéutico que utiliza productos derivados o extraídos de la colmena, entre los que se encuentran: miel de abejas, polen, propóleos, jalea real, veneno de abejas (apitoxina), cera, combinación de los productos anteriores ${ }^{7}$.

El propóleos posee una gran variedad de propiedades medicinales, entre las cuales se pueden mencionar su capacidad cicatrizante, anestésica, antiinflamatoria, antibacteriana antimicótica y antiviral, vasoprotectora y antitumoral. El propóleos también es antioxidante. Se pueden distinguir innumerables usos para su aplicación en variadas industrias: farmacéutica (tanto en medicina humana como medicina veterinaria), agrícola y en la industria alimentaria ${ }^{8-13}$.

Sus propiedades antimicrobianas, bacteriostáticas y bactericidas, son proporcionadas por los ácidos benzoico, oxibenzoico, metoxibenzoico, caféico, ferúlico, los sesquiterpenos y las flavononas (principalmente la galangina).

Las propiedades del propóleo pueden ser atribuídas fundamentalmente a los flavonoides pinocembrina, galangina, pinobanksina, pinobanksina3-acetato, éster bencil del ácido caféico. El ácido caféico es uno de los compuestos que intervienen en la actividad del propóleo contra Streptococcus aureus, Profeus vulgaris, Mycobacterium tuberculosis y Helminthosporium sp ${ }^{14,15}$.

La capacidad de los extractos de propóleo de contener el desarrollo de formas patógenas de virus, ha sido demostrada. Los flavonoides reve- 
lan una actividad antiviral bien definida, en particular la apigenina, acacetina y pectolinarigenina ${ }^{16}$.

\section{Aplicación Clínica}

Al propóleo se le atribuyen múltiples propiedades las cuales podrían llevar a que tengamos a disposición un excelente medio terapéutico tanto en la medicina humana como en la veterinaria.

Las investigaciones clínicas y de laboratorio corroboran la acción antimicrobiana y antimicótica de los preparados. Las soluciones inyectables presentan in vitro una buena acción antifúngica.

Diversos autores en el mundo reportan acerca de la efectividad del propóleo en la cura de heridas y en diversas afecciones estomatológicas como: en la cura de alveolitis y úlceras bucales, en la terapéutica periodontal, en la terapia pulpar ${ }^{17-23}$.

Bellón Leyva y Calzadilla Mesa, en un ensayo clínico, fase 2 aleatorizado, que consistió en la aplicación de la tintura de propóleo al 5\% para el tratamiento de la estomatitis aftosa demostraron una muy buena efectividad clínica, una rápida incorporación de los pacientes a sus actividades y mejoramiento de la calidad de vida, comparado con los métodos tradicionales ${ }^{24}$.

Gómez Porcegué y col. realizaron un estudio observacional descriptivo con carácter retrospectivo con el objetivo de determinar la efectividad del uso del propóleos al $5 \%$ en la evolución de los pacientes con alveolitis. Luego de realizárseles curetaje suave del alveolo y lavado con suero fisiológico se les aplicó propóleos al $5 \%$ con la ayuda de una jeringuilla. Su uso resultó efectivo ya que hubo remisión de los síntomas entre las 48 y 72 horas mayormente 25 .

El propóleo al $20 \%$ de forma tópica fue una terapia eficaz cuando se presentaron hiperestesias leves y moderadas. Se observó remisión de los síntomas de forma significativa a partir de las $48 \mathrm{~h}$, sin embargo, en la hiperestesia severa la probabilidad de eliminar el dolor a las $72 \mathrm{~h}$ fue del $50 \%{ }^{26}$.

El empleo de la tintura de propóleo al $5 \%$ en la cura de heridas sépticas faciales, ha mostrado una gran efectividad, ya que el $90 \%$ de los pacientes presentó una total mejoría en los primeros 7 días de tratamiento y sólo I paciente necesitó I 3 días para la cura total de la herida ${ }^{27}$.

El tratamiento con propóleos hidroalcohólico al $5 \%$ de sólidos solubles, resultó ser un tratamiento alternativo eficaz para las parotiditis cró- nicas recurrentes. La gravedad de la enfermedad no resultó ser un elemento significativo para la evolución de los pacientes, lo cual demuestra la eficacia del producto ${ }^{28}$.

En medicina, mediante la aplicación del propóleo en forma de curas locales se valoró sus resultados, tratando de beneficiar a las pacientes con un tratamiento inocuo y a la vez efectivo de esta enfermedad.

Jiménez y col. utilizaron tintura de propóleo al $15 \%$ en pacientes con cervicitis inespecífica y obtuvieron disminución de los síntomas y epitelización de la zona afectada en un período de 10 días $^{29}$.

Importantes estudios epidemiológicos realizados en Europa y Japón muestran que las poblaciones con mayor consumo de flavonoides, principales componentes del propóleos, tienen menor mortandad por enfermedad coronaria ${ }^{30}$.

\section{Conclusión}

La revisión de la literatura nos permite afirmar que las propiedades biológicas del propóleo, lo transforma en un producto de origen natural utilizable para diversas afecciones corporales.

Es un producto muy interesante que está siendo objeto de numerosas investigaciones, para mejorar su calidad, producción y comercialización.

Es de suma importancia poder incorporarlo a la odontología, debido a su bajo costo y a las propiedades y beneficios que puede aportar.

En la Facultad de Odontología de la Universidad Nacional del Nordeste, se encuentran en ejecución dos proyectos de investigación referidos a la actividad in vitro del propóleos contra bacterias aisladas de caries y alveolitis. 


\section{Bibliografía}

I. Seeley TD. Honeybee ecology. A study of adaptation in social life. Princeton, New Jersey: Princeton University Press; 1985.

2. Kartal M, Yildiz S, Kaya S, Kurucu S, Topçu G. Antimicrobial activity of propolis samples from two different regions of Anatolia. Journal of Ethnopharmacology 2003; 86 (I): 69 - 73.

3. Gómez AM, Gómez GM, Arráez D, Segura A, Fernández A. Advances of phenolic compounds in product derived from bees. Journal of Pharmaceutical and Biomedical Analysis 2006; 4 I (4): 1220 - 1234.

4. Palomino García LR, Martínez Galán JP, García Pajón CM, Gil González JH, Durango Restrepo DL. Caracterización Fisicoquímica y Actividad Antimicrobiana del Propóleos en el Municipio de La Unión (Antioquia, Colombia). Rev Fac Nal Agr Medellín 2010; 63 (I): 5373 - 5383.

5. Bedascarrasbure E, Maldonado L, Alvarez A, Rodríguez E. Contenido de Fenoles y Flavonoides del Propoleos Argentino. Acta Farm. Bonaerense 2004, 23 (3): 369 - 72.

6. Organización Mundial de la Salud Tradicional. Complementary and alternative medicines and therapies. Washington DC. Regional de la OMS para Las Américas. OPS (Grupo de Trabajo OPS/ OMS); 1999.

7. Gordon J. Alternative medicine and the family phisicians. Am Fam Phys 1996; 54 (7): 2205-12.

8. Marcucci M. C. Propolis: Chemical composition, biological properties and therapeutic activity. Apidologie 1995; 26: 83 - 99.

9. Mirzoeva O., Grishain R., Calder P. Antimicrobial actions of propolis and some of its components: the effects on growth, membrana potential and motility of bacteria. Microbiol Res 1997; I52 (3): $45-49$.

10. Özcan M. Uso de extracto de propóleos como antioxidante natural para aceites vegetales. Revista del Instituto de la Grasa 2000; 5 I (4): 25I-253.

II. Vynograd N, Vynogrand I., Sosnowski Z. A comparative mult-centre study of the efficacy of proplis acycloir and placebo in the treatment of geni- tal herpes. Phytomedicine 2000; 7 (I): I - 6.

12. Matsuka M. Criteria of propolis in Japan. Japan Propolis Conference and Japan Health Food \& Nutrition Food Association. 2000; pp. 4.

13. Banshota A.H. Recent progress in pharmacological research of propolis. Phytother Res 200I; 15: 56 I - 57I.

14. Farré R, Frasquet I, Sánchez A. El própolis y la salud. Ars Pharmaceutica 2004, 45: I; 2 I - 43.

15. Manrique AJ. Antimicrobial activity of propolis from two climatic zones in Miranda state, Venezuela. Seasonal variation effect. Zootecnia Trop 2006, 24 (I): 43 - 53.

16. 16. Kujumgiev A, I. Tsvetkova, Y. Serkedjieva, V. Bankova, R. Christov y S. Popov. 1999. Antibacterial, antifungal and antiviral activity of propolis of different geographic origin. J Ethnopharm 1999, 64: 235 - 240.

17. Pang JF. Treatment of oral leukoplasia with propolis. Report 45 cases. Chuhsilchich Hotsacnich 1985;5 (8): 485 - 8.

18. Gafar M. The treatment of simple pulp gangrene with the apitherapeutic agent "Propolis". Rev Chir (Stomatol) 1986; 33 (2): 15 - 8.

19. Martínez G, Gou Godoy A, Oña R, Palmer MC, Falcón MA. Estudio preliminar sobre los efectos del propóleo en el tratamiento de la gingivitis crónica y las úlceras bucales. Rev cubana Estomatol 1988; 25 (3): 36 - 43.

20. Sumano H, Ocampo, Gaytán G, González M. Eficiencia cicatrizante de varios medicamentos de patente; la sábila y el propóleo. Veterinaria México 1989;18 (I): 33 - 7.

21. Quintana Díaz JC. El uso de la propolina al $8 \%$ en el tratamiento de la alveolitis. Rev Cubana Estomatol 1992 (2): 93 - 7.

22. Martínez G, Alfonso E, Ortega L, Gou Godoy A. Efectos curativos de una solución hidroalcohólica del propóleo cubano en la terapéutica parodontal. Rev Cubana Estomatol 1992; (I): 14 - 9.

23. León García C, García E. Efectos del propóleo en el tratamiento de aftas bucales. Rev Cubana Med Milit 1993; 22 (I): 42- 5. 
24. Bellón Leyva S, Calzadilla Mesa XM. Efectividad del uso del propóleo en el tratamiento de la estomatitis aftosa. Rev Cubana Estomatol [revista en la Internet]. 2007 Sep [consultado 20II Mayo I8]; 44(3): 0-0. Disponible en: http://www.sld.cu/ galerias/pdf/sitios/mednat/efectividad_del_uso_ del_propoleo_en_el_tratamiento_de_la_estomatitis_aftosa.pdf

25. Gómez Porcegué Y, Vilvey Pardillo L, Sánchez Rodríguez L, Diaz Valdés L. El uso del propóleos al $5 \%$ en el tratamiento de la alveolitis. Gaceta Médica Espirituana [serie en internet]. 2008 [consultado 2 sep 2008]; 10 (I). [aprox. 19 p.]. Disponible en: http://bvs.sld.cu/revistas/gme/pub/ vol.I0.(I)_06/p6.html

26. Fernández Gerpe KI, Martín Reyes O, Arias Herrera S, Paz Latorre E. Eficacia de la tintura de propóleo al $20 \%$ en el tratamiento de la hiperestesia dentinaria. Archivo Médico de Camagüey 2007; II(5) [consultado 20II Mayo 19], Disponible en: http://www.amc.sld.cu/amc/2007/ vl In5-2007/2243.htm.

27. Quintana Díaz JC, Alonso Rodríguez O, Díaz Velázquez M, López Milián M. Empleo de la tintura de propóleo al $5 \%$ en la cura de heridas sépticas faciales. Rev Cubana Estomatol [revista en la Internet]. 1997 Jun [consultado 201 I Mayo 19; 34 (I): 25-27. Disponible en: http://scielo.sld. cu/scielo.php?script $=$ sci_arttext\&pid $=$ S003475071997000 100005\&lng=es.

28. Vila Morales Dadonim, Pi Osoria Andrés, Giral Rivera Teresa, González-Longoria Concepción Rebeca. Aplicación del propóleos en el tratamiento de la parotiditis crónica del niño. Rev Cubana Estomatol [revista en la Internet]. 2009 Dic [consultado 20II Mayo 19]; 46(4): 42-49. Disponible en:http://scielo.sld. cu/ scielo.php?script=sci_arttext\&pid=S003475072009000400005\&lng=es.

29. Jiménez ZL, Martínez J, Montes JM, Monilia C, Pérez I. Aplicación del propóleo en las heridas quirúrgicas sépticas. En: Investigaciones Cubanas sobre el propóleo. Matanzas: Consejo Científico del Instituto de Medicina Veterinaria; 1989.

30. Hertog MGL, Kromhout D, Aravanis C, Blackburn H, Buzina R, Fidanza F, Giampaoli $S$, Jansen A, Menotti A, Nedeljkovic S, Pekkaarinen M, Simic BS, Toshima H, Feskens EJM, Hollman $\mathrm{PCH}$, Katan MB. Flavonoid intake and long-term risk of coronary heart disease and cancer in the seven countries study. Arch Intern Med 1995; 155: 38 | - 86 . 